\title{
Effect of foliar application of brassinolide on photosynthesis and chlorophyll fluorescence traits of Leymus chinensis under varying levels of shade
}

\author{
A.J. YANG ${ }^{*}$, S.A. ANJUM ${ }^{*}$,**, L. WANG ${ }^{*}$, J.X. SONG*, X.F. ZONG ${ }^{*}$, J. LV*, A. ZOHAIB ${ }^{* *}$, I. ALI**, \\ R. YAN ${ }^{*}$, Y. ZHANG ${ }^{*}$, Y.F. DONG ${ }^{*}$, and S.G. WANG ${ }^{*,+}$ \\ College of Agronomy and Biotechnology, Southwest University, Chongqing 400716, China* \\ Department of Agronomy, University of Agriculture, Faisalabad 38040, Pakistan ${ }^{* *}$
}

\begin{abstract}
The present study was conducted to determine the effect of exogenous application of brassinolide (BR) on Leymus chinensis grown under shade, i.e., control (100\% natural light), mild shade ( $70 \%$ natural light), and moderate shade (50\% natural light). Shade substantially enhanced the plant growth, synthesis of photosynthetic pigments, photosynthetic efficiency, and chlorophyll (Chl) fluorescence attributes of L. chinensis as compared with control. The order of increase was mild shade $>$ moderate shade $>$ natural light except Chl content, where the order of increase was moderate shade $>$ mild shade $>$ natural light. Likewise, application of BR resulted in further exacerbation of plant height, plant fresh and dry mass, but less in case of $\mathrm{Chl}$ and carotenoids contents, gas-exchange characteristics, and Chl fluorescence attributes. The results conclude that shade significantly enhanced plant growth through alterations in physiological attributes of L. chinensis, while, application of BR may not further improve the plant growth under shade.
\end{abstract}

Additional key words: chlorophyll pigment; gas exchange; photosynthetic diurnal variation; plant height; plant mass.

\section{Introduction}

Leymus chinensis (Trin.) Tzvel. is a perennial plant native to China with good palatability and high forage value. The grassland, where it dominates, spreads widely from the southern Chinese loess plateau to the northern Russian Baikal, and from the Sanjiang plain of eastern China to Ulan Bator in Mongolia. The dominance of L. chinensis in semiarid grasslands usually varies along the gradients of water and nutrient availability (Wang and $\mathrm{Li}$ 1996). Herbivores can affect plants directly by removing biomass and indirectly by modifying resource availability (e.g., enhancing light penetration, altering water uptake, redistribution of nutrients, and/or reducing carbon assimilation due to leaf removal) (van der Wal et al. 2000, Augustine 2003, Gassmann 2004, Hodgkinson and Müller 2005) or differential grazing on neighboring plants (Augner et al. 1997, Haag et al. 2004). The importance of resource availability and disturbances as well as their interactions on plant community structure and species diversity has been widely reported (Wilson and Tilman 2002, Fynn et al. 2005). However, the increase in grazing pressure, coupled with abiotic stresses such as drought, salinity, temperature, and light regimes, has led to a substantial reduction in canopy cover throughout much of the grassland.

Light is the main environmental factor for plants to provide energy for plant photosynthesis, light intensity is not conducive to plant growth. Although severely low light conditions can reduce the photosynthetic efficiency of

Received 14 June 2016, accepted 10 May 2017, published as online-first 12 June 2017.

${ }^{+}$Corresponding author; e-mail: wangsg@swu.edu.cn

Abbreviations: APX - ascorbate peroxidase; $\mathrm{BR}$ - brassinolide; $C_{\mathrm{i}}$ - intercellular $\mathrm{CO}_{2}$ concentration; Car - carotenoids; $\mathrm{CAT}$ - catalase; $\mathrm{Chl}$ - chlorophyll; $E$ - transpiration rate; CUE - carboxylation utilization; DAT - days after treatment; $\mathrm{F}_{0}$ - minimal fluorescence yield of the dark-adapted state; $F_{m}$ - maximal fluorescence yield of the dark-adapted state; $F_{s}$ - steady-state fluorescence; $F_{m}{ }^{\prime}-m_{a x i m a l}$ fluorescence yield of the light-adapted state; $\mathrm{F}_{\mathrm{v}} / \mathrm{F}_{\mathrm{m}}$ - optimal/maximal quantum yield of PSII photochemistry; $\mathrm{F}_{\mathrm{v}} / \mathrm{F}_{0}-$ optimal $/$ minimal quantum yield of PSII or photochemical efficiency of PSII; $F_{v}$ - variable fluorescence; $g_{s}$ - stomatal conductance; GR - glutathione reductase; $\mathrm{L}_{\mathrm{s}}$ - stomatal limitation; $P_{\mathrm{N}}$ - net photosynthetic rate; PGRs - plant growth regulators; POD - peroxidase; ROS - reactive oxygen species; SOD - superoxide dismutase; SUE - sunlight-utilization efficiency; TChl - total chlorophyll content; WUE - wateruse efficiency; ФPSI - effective quantum yield of PSII photochemistry.

Acknowledgement: The authors are grateful to National Key Basic Research Program of China (2014CB138806) along with Crop Germplasm Resources Utilization and Innovation Base Program of the 111 Project of China (104510-205001). 
plants leading to limited plant growth, an excess light can also hinder the plant growth and development. Under low light conditions the plants may experience reduced activity of Rubisco resulting in lowered $\mathrm{CO}_{2}$ assimilation rate (Stitt and Schulze 1994), ultimately causing a decreased growth. On the other hand, exposure of plants to excessive light can cause photoinhibition through energy imbalance. This process is associated with rapidly reversible downregulation of PSII photochemical efficiency or with maintenance of the slow reversible energy-dissipating mechanisms, with repair processes or with the eternal destruction of photosynthetic apparatus (Allen and Ort 2001). However, reasonable shading can not only prevent the plant from excessive light but also improves the micrometeorological conditions of crop growth and photosynthetic capacity of plants (Tang et al. 2015). This indicates that determination of optimum level of irradiance is important for better plant growth and regulation of plant growth under different light regimes. However, since fifties of the $20^{\text {th }}$ century, it is expected that the amount of short-wave solar radiation reaching the Earth is reduced by $27 \%$ every ten years leading to global diming of sunlight. Studying the effects of light intensity on L. chinensis can unveil the possible impacts of light intensity and global diming conditions on the productivity of L. chinesis and other crop plants (Zhu et al. 2010). Chl fluorescence has always been used in studies of the photosynthetic regulation and the plant responses to environment because of its sensitivity, suitability, and nondestructive features (Dai et al. 2009). Photoinhibition of PSII can be easily sensed in vivo by reduction in 'dark-adapted' ratio of variable to maximum $\mathrm{Chl} a$ fluorescence, i.e., $\mathrm{F}_{\mathrm{v}} / \mathrm{F}_{\mathrm{m}}$ (Krause and Weis 1991).

Plant growth regulators (PGRs) are increasingly used

\section{Materials and methods}

Experimental material: Pot experiment was carried out to determine the effect of BR on one-year-old L. chinensis plants grown under various levels of shade at the College of Agronomy and Biotechnology, Southwest University, Chongqing, China. The experimental area is located between latitudes of $29^{\circ} 49^{\prime} 32^{\prime \prime} \mathrm{N}$, longitudes $106^{\circ} 26^{\prime} 02^{\prime \prime}$ $\mathrm{E}$, and altitude of $220 \mathrm{~m}$. Irradiance is about 1,200 annual sunshine hours. The average PAR was $1,135 \mu \mathrm{mol}$ (photon) $\mathrm{m}^{-2} \mathrm{~s}^{-1}$ for May and June 2015. The average temperature was $18.2^{\circ} \mathrm{C}$ and the annual precipitation was $1,200 \mathrm{~mm}$. for the improvement of plant growth and stress resistance. Brassinolide (BR) is a kind of hormone, which is recognized as the most active, highly efficient, broadspectrum, and nontoxic plant growth hormone. The main function of BR is to promote the plant growth and increase the yield of crops. In addition, BR improves the photosynthetic efficiency of plants mainly through enhanced biosynthesis of photosynthetic pigments and protection of photosynthetic machinery from damaging effects of reactive oxygen species (ROS) through enhanced accumulation of osmolytes and improved activity of antioxidant enzymes under both normal and stressed conditions as well (Cao et al. 2009, Wang et al. 2016). Niu et al. (2016) reported that exogenous application of BR on L. chinensis enhanced the plant height, leaf area, dry mass accumulation, biosynthesis of photosynthetic pigments, stimulated the accumulation of osmolytes, and increased the activity of antioxidant enzymes, such as superoxide dismutase (SOD), peroxidase (POD), catalase (CAT), ascorbate peroxidase (APX), and glutathione reductase (GR), while lowering down the production and activity of ROS under both normal and high temperature stress conditions. Similarly, Wang et al. (2016) perceived increased growth, biosynthesis of photosynthetic pigments, and exaggerated activity of enzymatic antioxidants (SOD, POD, CAT, GR, APX, etc.) in L. chinensis plants in response to exogenous application of BR under chilling stress. Considering the promising effects of shade and BR on plant morphological, physiological, and biochemical attributes, the present study was conducted with the aim to evaluate the effect of BR application on growth and photosynthetic efficiency of $L$. chinensis under normal and different levels of shade.

Seeds of L. chinensis plants were sown in dishes containing sand for germination in laboratory in July 2014, followed by transplanting of seedlings in pots (diameter of $24.5 \mathrm{~cm}$ and height of $20 \mathrm{~cm}$ ). Plants were allowed to grow until April, 2015. Consistently growing uniform seedlings were selected as experimental material.

Treatments: The experiment consisted of six treatments with spraying of $0.1 \mathrm{mg}(\mathrm{BR}) \mathrm{L}^{-1}$ solution on plants exposed to three different levels of shade:

\section{Treatment}

\begin{tabular}{lll}
\hline $\mathrm{T}_{0}$ & Control & $100 \%$ natural light \\
$\mathrm{T}_{1}$ & Mild shade & $70 \%$ natural light \\
$\mathrm{T}_{2}$ & Moderate shade & $50 \%$ natural light \\
$\mathrm{BT}_{0}$ & Control $+\mathrm{BR}$ & $100 \%$ natural light $+0.1 \mathrm{mg}(\mathrm{BR}) \mathrm{L}^{-1}$ \\
$\mathrm{BT}_{1}$ & Mild shade $+\mathrm{BR}$ & $70 \%$ natural light $+0.1 \mathrm{mg}(\mathrm{BR}) \mathrm{L}^{-1}$ \\
$\mathrm{BT}_{2}$ & Moderate shade $+\mathrm{BR}$ & $50 \%$ natural light $+0.1 \mathrm{mg}(\mathrm{BR}) \mathrm{L}^{-1}$ \\
\hline
\end{tabular}


Brassinolide (Sigma-Aldrich Company, USA) was dissolved with ethanol and then diluted with distilled water to $0.1 \mathrm{mg} \mathrm{L}^{-1}$. For creating different levels of shade, a shade shed was built on 18 May, 2015. The area of the shade shed was $400 \mathrm{~cm} \times 200 \mathrm{~cm}$, and the height from ground was $1 \mathrm{~m}$. Two treatments were placed under the same shade conditions, i.e., $\mathrm{T}_{0}$ and $\mathrm{BT}_{0}, \mathrm{~T}_{1}$ and $\mathrm{BT}_{1}$, and $\mathrm{T}_{2}$ and $\mathrm{BT}_{2}$. Each treatment was replicated five times. BR was applied three times, i.e., 19 May, 26 May, and 2 June, in evening at 18:00 $\mathrm{h}$ to avoid the effect of light. Each pot was supplied with $25 \mathrm{ml}$ of Hoagland's nutrient solution every $5 \mathrm{~d}$ to ensure suitable nutrient supply. Water was applied to each pot every $2 \mathrm{~d}$.

Measurements: After the treatments, data were recorded regarding growth, photosynthetic pigments, gas-exchange characteristics, and $\mathrm{Chl}$ fluorescence parameters three times at different durations. Growth, photosynthetic pigments, and gas-exchange characteristics were measured 20, 40, and $60 \mathrm{~d}$ after the imposition of treatments (DAT). Furthermore, photosynthetic diurnal variation was determined on 20 July with an interval of $2 \mathrm{~h}$ from 6:0018:00 h. Chl fluorescence attributes were measured 6, 12, and 18 DAT.

Growth attributes: Plants were uprooted and plant were rinsed with tap water followed by $2-3$ times rinsing with distilled water. The plant height was measured from the tip of the stem to parietal lobe at the base of plants. Adhered water was absorbed from the seedlings by using filter paper. Fresh mass (FM) of seedlings was determined by weighing the seedlings and then drying by placing the seedlings in oven at $105^{\circ} \mathrm{C}$ for 30 min followed by drying at $65^{\circ} \mathrm{C}$ till constant mass in order to obtain the seedling dry mass (DM).

Photosynthetic pigments: $\mathrm{Chl} a$, Chl $b$, total Chl (TChl), and carotenoid (Car) contents were measured by Wellburn (1994) method. A leaf sample of $0.1 \mathrm{~g}$ was ground and placed in $15-\mathrm{mL}$ centrifuge tube along with $10 \mathrm{~mL}$ of miscible liquids by $95 \%$ acetone and absolute ethyl alcohol $(1: 1, \mathrm{v} / \mathrm{v})$. Then it was covered with black plastic bag and kept at dark place until the samples changed into white color. The absorbance was measured at $665,649,470$, and

\section{Results}

Shade increased plant growth and development of L. chinensis at all levels which was further enhanced by exogenous application of BR. The plant height increased from 20 to $40 \mathrm{DAT}$, but then declined at $60 \mathrm{DAT}$. However, plant FM and DM increased linearly from 20 to 60 DAT. Shade enhanced the plant growth as compared to natural light (control) and the pattern of increase in growth was in the order of mild shade $>$ moderate shade $>$ natural light. Application of BR enhanced the plant height, plant
$652 \mathrm{~nm}$, respectively, by a spectrophotometer $(U V-6000$, Shanghai Metash Instrument Co. Ltd, China ).

Gas exchange: The gas-exchange characteristics of L. chinensis leaves were measured in the morning (10:00 11:30 h) each time using the LI-6400 portable measuring instrument under synthetic PAR of $1,000 \mu \mathrm{mol}$ (photon) $\mathrm{m}^{-2} \mathrm{~s}^{-1}$ for different treatments. The ecophysiological indexes measured included the net photosynthetic rate $\left(P_{\mathrm{N}}\right)$, intercellular $\mathrm{CO}_{2}$ concentration $\left(C_{\mathrm{i}}\right)$, stomatal conductance $\left(g_{\mathrm{s}}\right)$, transpiration rate $(E)$, sunlight-utilization efficiency (SUE), water-use efficiency (WUE), carboxylation utilization (CUE), and stomatal limitation $\left(\mathrm{L}_{\mathrm{s}}\right)$. Each index was measured three times, and the average value was taken. Similarly, $P_{\mathrm{N}}, g_{\mathrm{s}}$, and $E$ were recorded every two h $(6: 00-18: 00 \mathrm{~h})$ on 20 July in order to undermine the photosynthetic diurnal variation.

Chl fluorescence parameters were determined using an open gas-exchange system (LI-6400; LI-COR, Inc., Lincoln, NE, USA) with an integrated fluorescence chamber (LI-6400-40 leaf chamber fluorometer). Five plants were selected and their leaves were dark-adapted for $20 \mathrm{~min}$, and then irradiated with weak light $[0.1 \mu \mathrm{mol}$ (photon) $\mathrm{m}^{-2} \mathrm{~s}^{-1}$. The minimal fluorescence yield of the dark-adapted state $\left(\mathrm{F}_{0}\right)$ was measured, and then 0.8 -s saturation pulse light $\left[3,000 \mu \mathrm{mol}\right.$ (photon) $\left.\mathrm{m}^{-2} \mathrm{~s}^{-1}\right]$ was used to determine the maximal fluorescence yield of the dark-adapted state $\left(\mathrm{F}_{\mathrm{m}}\right)$. In leaves, the steady-state fluorescence $\left(\mathrm{F}_{\mathrm{S}}\right)$ was measured after 30-min light adaptation and the maximal fluorescence yield of the lightadapted state $\left(\mathrm{F}_{\mathrm{m}}{ }^{\prime}\right)$ was measured by 0.8 -s saturation pulse light $\left[3,000 \mu \mathrm{mol}\right.$ (photon) $\left.\mathrm{m}^{-2} \mathrm{~s}^{-1}\right]$. Optimal/maximal quantum yield of PSII or photochemical efficiency of PSII was calculated as: $F_{\mathrm{v}} / \mathrm{F}_{\mathrm{m}}=\left(\mathrm{F}_{\mathrm{m}}-\mathrm{F}_{0}\right) / \mathrm{F}_{\mathrm{m}}$, optimal $/$ minimal quantum yield of PSII was calculated as: $\mathrm{F}_{\mathrm{v}} / \mathrm{F}_{0}=\left(\mathrm{F}_{\mathrm{m}}-\mathrm{F}_{0}\right) / \mathrm{F}_{0}$, and photosynthetic quantum yield of PSII was calculated as: $\Phi_{\text {PSII }}=\left(\mathrm{F}_{\mathrm{m}}{ }^{\prime}-\mathrm{F}_{\mathrm{s}}\right) / \mathrm{F}_{\mathrm{m}}{ }^{\prime}$.

Statistical analysis: The data were analyzed using Microsoft Excel and SPSS statistical software. The single factor analysis of variance ( $A N O V A)$ was used for analysis of data and Duncan's multiple range test was used to compare the means at $5 \%$ probability level.

FM and DM under natural light by $4-8 \%, 13-29 \%$, and $10-15 \%$, respectively; under mild shade by $2-6 \%, 14$ $16 \%$, and $4-17 \%$, respectively, and under moderate shade conditions by $2-3 \%, 8 \%$, and $8 \%$, respectively, as compared with their respective controls (Table 1, Fig. 1).

Biosynthesis of photosynthetic pigments significantly increased due to shade; BR sprayed on L. chinensis resulted in further enhancement at each level of shade, but the increase was not statistically significant. Chl $a, b$, 
Table 1. Effect of BR on morphological attributes and photosynthetic pigments of Leymus chinensis under different light intensities after $60 \mathrm{~d}$ of treatments. Car - carotenoids, Chl - chlorophyll, TChl - total chlorophyll content, $\mathrm{T}_{0}-100 \%$ natural light, $\mathrm{T}_{1}-$ mild shade (70\% natural light), $\mathrm{T}_{2}$ - moderate shade (50\% natural light), $\mathrm{BT}_{0}-100 \%$ natural light $+0.1 \mathrm{mg}(\mathrm{BR}) \mathrm{L}^{-1}, \mathrm{BT}_{1}-\mathrm{mild}_{\mathrm{l}}$ shade $+\mathrm{BR}[70 \%$ natural light $\left.+0.1 \mathrm{mg}(\mathrm{BR}) \mathrm{L}^{-1}\right], \mathrm{BT}_{2}-$ moderate shade $+\mathrm{BR}\left[50 \%\right.$ natural light $\left.+0.1 \mathrm{mg}(\mathrm{BR}) \mathrm{L}^{-1}\right]$. Values are means $\pm \mathrm{SE}(n=5)$. Values followed by the same letter within columns are not significantly different according to Duncan's multiple range test $(p<0.05)$.

\begin{tabular}{lllllllll}
\hline $\begin{array}{l}\text { Treatment Plant height } \\
{[\mathrm{cm}]}\end{array}$ & $\begin{array}{l}\text { Fresh mass } \\
{[\mathrm{mg} \text { per plant] }}\end{array}$ & $\begin{array}{l}\text { Dry mass } \\
{[\mathrm{mg} \text { per plant }]}\end{array}$ & $\begin{array}{l}\text { Chl } a \\
{\left[\mathrm{mg} \mathrm{g}^{-1}\right]}\end{array}$ & $\begin{array}{l}\text { Chl } b \\
{\left[\mathrm{mg} \mathrm{g}^{-1}\right]}\end{array}$ & Chl a/b & $\begin{array}{l}\text { TChl } \\
{\left[\mathrm{mg} \mathrm{g}^{-1}\right]}\end{array}$ & $\begin{array}{l}\text { Car } \\
{\left[\mathrm{mg} \mathrm{g}^{-1}\right]}\end{array}$ \\
\hline $\mathrm{T}_{0}$ & $32.50 \pm 0.38^{\mathrm{e}}$ & $533.1 \pm 9.2^{\mathrm{d}}$ & $183.7 \pm 3.1^{\mathrm{d}}$ & $1.57 \pm 0.01^{\mathrm{b}}$ & $0.77 \pm 0.04^{\mathrm{c}}$ & $2.02 \pm 0.09^{\mathrm{a}}$ & $2.18 \pm 0.01^{\mathrm{cd}}$ & $0.219 \pm 0.013^{\mathrm{c}}$ \\
$\mathrm{BT}_{0}$ & $33.73 \pm 0.22^{\mathrm{d}}$ & $612.6 \pm 4.3^{\mathrm{c}}$ & $204.0 \pm 1.7^{\mathrm{cd}}$ & $1.72 \pm 0.09^{\mathrm{ab}}$ & $0.85 \pm 0.05^{\mathrm{c}}$ & $2.03 \pm 0.03^{\mathrm{a}}$ & $2.07 \pm 0.33^{\mathrm{d}}$ & $0.220 \pm 0.000^{\mathrm{c}}$ \\
$\mathrm{T}_{1}$ & $38.15 \pm 0.56^{\mathrm{b}}$ & $733.7 \pm 16.2^{\mathrm{b}}$ & $264.1 \pm 3.1^{\mathrm{ab}}$ & $1.82 \pm 0.04^{\mathrm{a}}$ & $1.29 \pm 0.05^{\mathrm{b}}$ & $1.41 \pm 0.08^{\mathrm{bc}}$ & $2.60 \pm 0.11^{\mathrm{cd}}$ & $0.257 \pm 0.011^{\mathrm{b}}$ \\
$\mathrm{BT}_{1}$ & $40.43 \pm 0.22^{\mathrm{a}}$ & $851.3 \pm 8.1^{\mathrm{a}}$ & $274.0 \pm 4.2^{\mathrm{a}}$ & $1.80 \pm 0.04^{\mathrm{a}}$ & $1.26 \pm 0.03^{\mathrm{b}}$ & $1.43 \pm 0.00^{\mathrm{b}}$ & $2.73 \pm 0.00^{\mathrm{bc}}$ & $0.269 \pm 0.000^{\mathrm{b}}$ \\
$\mathrm{T}_{2}$ & $34.53 \pm 0.09^{\mathrm{cd}}$ & $642.0 \pm 3.2^{\mathrm{c}}$ & $212.7 \pm 2.4^{\mathrm{cd}}$ & $1.88 \pm 0.09^{\mathrm{a}}$ & $1.63 \pm 0.01^{\mathrm{a}}$ & $1.16 \pm 0.06^{\mathrm{d}}$ & $3.26 \pm 0.12^{\mathrm{ab}}$ & $0.274 \pm 0.007^{\mathrm{ab}}$ \\
$\mathrm{BT}_{2}$ & $35.52 \pm 0.58^{\mathrm{c}}$ & $690.7 \pm 5.7^{\mathrm{bc}}$ & $230.6 \pm 4.6^{\mathrm{bc}}$ & $1.92 \pm 0.05^{\mathrm{a}}$ & $1.62 \pm 0.01^{\mathrm{a}}$ & $1.19 \pm 0.03^{\mathrm{cd}}$ & $3.35 \pm 0.21^{\mathrm{a}}$ & $0.299 \pm 0.003^{\mathrm{a}}$ \\
\hline
\end{tabular}

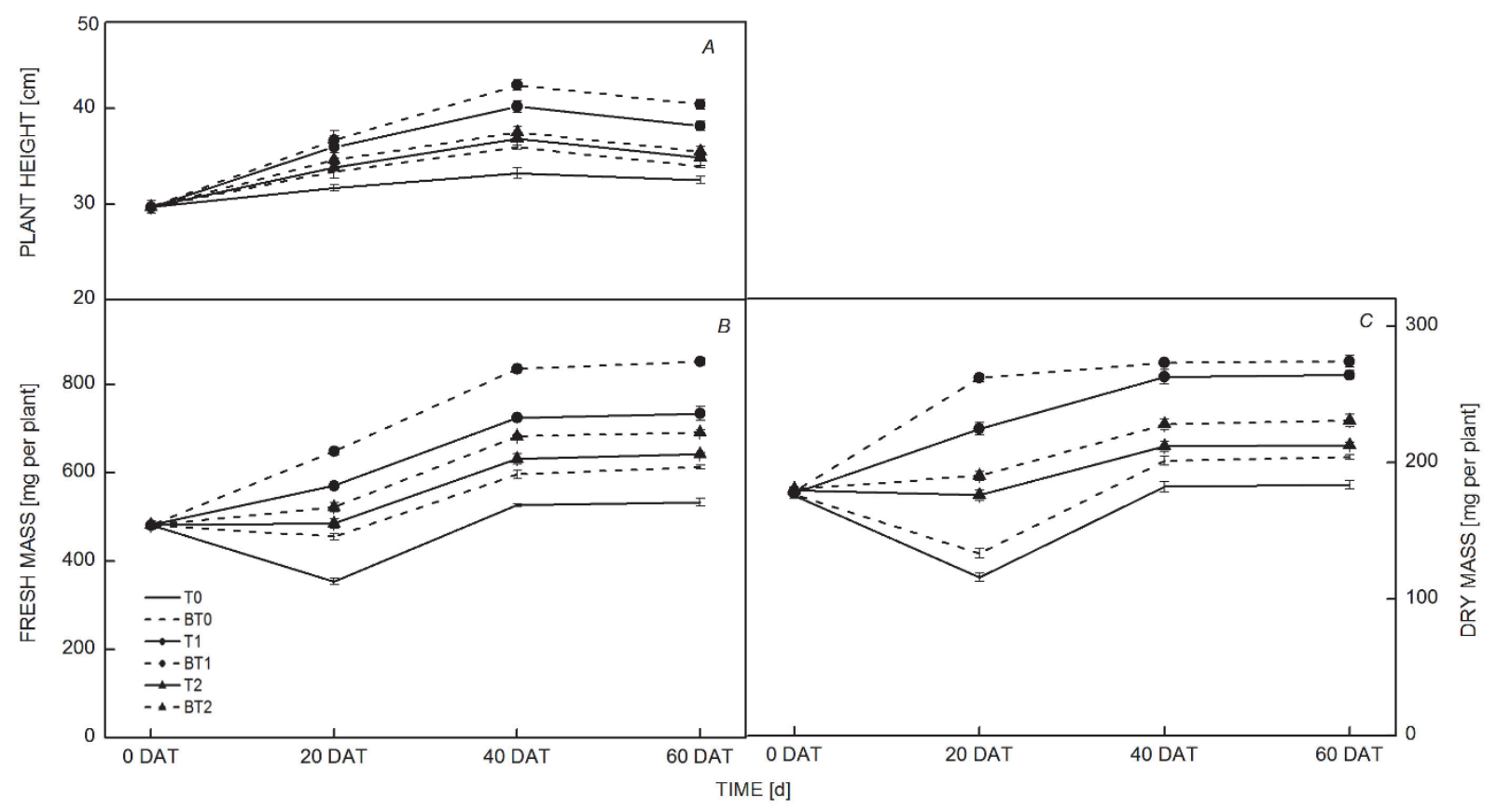

Fig. 1. Dynamic changes after BR treatment on plant height, fresh and dry mass of Leymus chinensis under different light intensities. Mean values \pm SE $(n=5)$, DAT - days after treatment, $\mathrm{T}_{0}-100 \%$ natural light, $\mathrm{T}_{1}-$ mild shade $(70 \%$ natural light), $\mathrm{T}_{2}$ - moderate shade $(50 \%$ natural light $), \mathrm{BT}_{0}-100 \%$ natural light $+0.1 \mathrm{mg}(\mathrm{BR}) \mathrm{L}^{-1}, \mathrm{BT}_{1}-$ mild shade $+\mathrm{BR}[70 \%$ natural light + $\left.0.1 \mathrm{mg}(\mathrm{BR}) \mathrm{L}^{-1}\right], \mathrm{BT}_{2}-$ moderate shade $+\mathrm{BR}\left[50 \%\right.$ natural light $\left.+0.1 \mathrm{mg}(\mathrm{BR}) \mathrm{L}^{-1}\right]$.

TChl, and Car increased from 20 to 40 DAT and then tended to decrease at $60 \mathrm{DAT}$; however, Chl $a / b$ ratio decreased linearly from 20 to 60 DAT. An increase in the biosynthesis of photosynthetic pigments was perceived by the effect of shade on L. chinensis as compared to natural light conditions (control). The increase in photosynthetic pigments followed the order: moderate shade $>$ mild shade $>$ natural light, except for the $\mathrm{Chl} a / b$ ratio, where the order was natural light $>$ mild shade $>$ moderate shade (Table 1 , Fig. 2).

The $P_{\mathrm{N}}$ was elevated during the day time from 6:00 until 10:00 $\mathrm{h}$ and then declined up to $14: 00 \mathrm{~h}$ followed by an increase at 16:00 $\mathrm{h}$ and again decline at 18:00 at each level of shade. Day mean values indicated that shade enhanced $P_{\mathrm{N}}$ and BR spray further boosted up $P_{\mathrm{N}}$, but this increase and effect was not statistically significant. At 10:00 h, when $P_{\mathrm{N}}$ was the highest one, shade significantly stimulated $P_{\mathrm{N}}$ over normal natural light conditions and maximum $P_{\mathrm{N}}$ was observed under mild shade, which was statistically the same as moderate shade. At peak sunshine hours, i.e., 12:00 and 14:00 h, shade again increased $P_{\mathrm{N}}$ significantly. At 8:00 h, when light was weak, shade significantly decreased the $P_{\mathrm{N}}$ and BR did not help mitigate negative effects of shade at that light intensity. The maximum $g_{\mathrm{s}}$ occurred at 8:00 h, after which it declined and increased again at 18:00 $\mathrm{h}$ at each level of shade. Shade and BR treatments did not influence the $g_{\mathrm{s}}$ significantly, however, an increase was observed in day mean values under shade. The maximum $E$ was observed at 10:00 h, but then decreased at 12:00 $\mathrm{h}$ and again decreased up to 18:00 $\mathrm{h}$ 


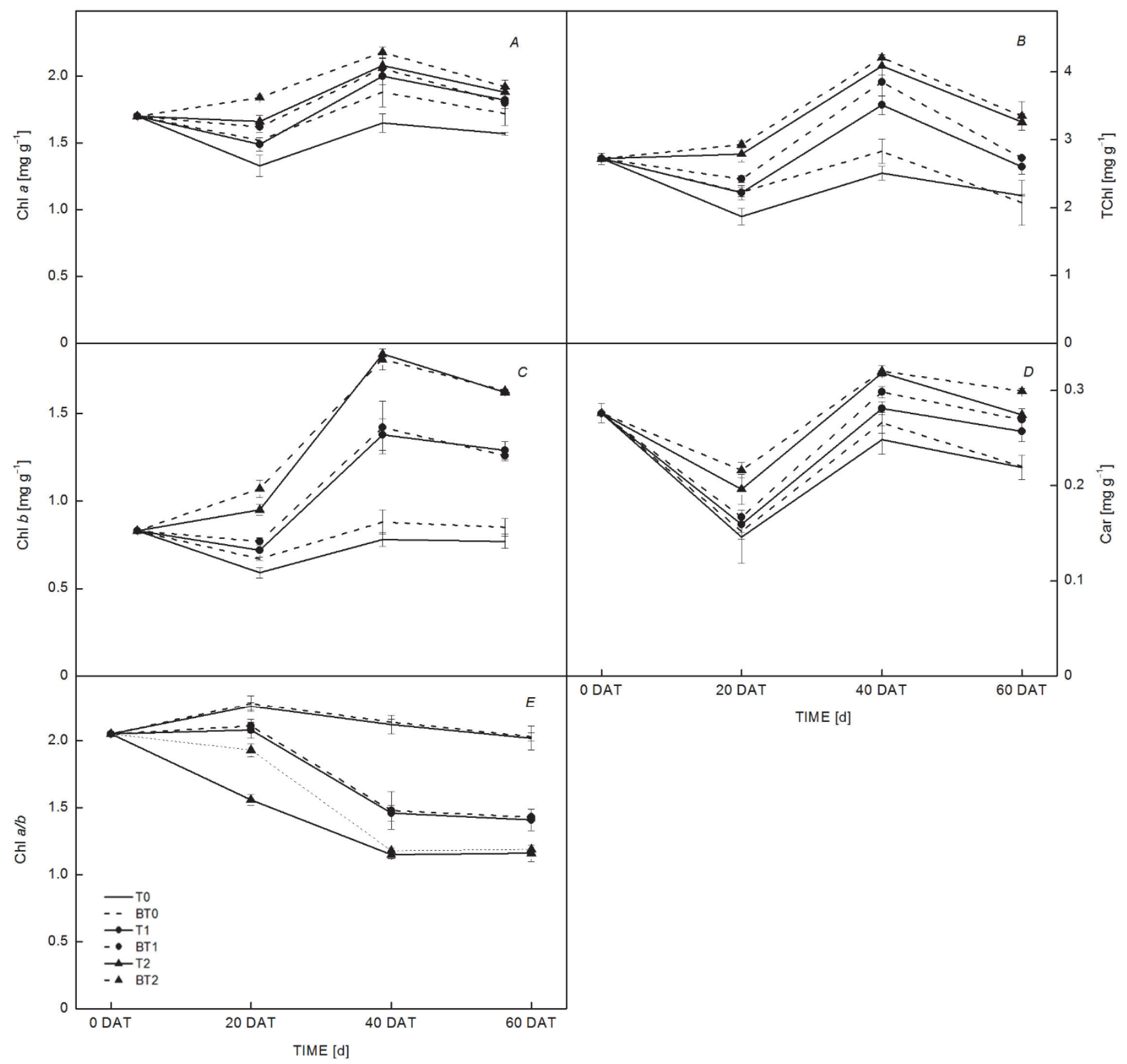

Fig. 2. Dynamic changes after BR treatment on $\mathrm{Chl} a$, Chl $b$, Chl $a / b$, TChl, and Car of Leymus chinensis under different light intensities. Mean value $\pm \mathrm{SE}(n=5)$, DAT - days after treatments. Car - carotenoids, Chl - chlorophyll, TChl - total chlorophyll content, $\mathrm{T}_{0}-$ $100 \%$ natural light, $\mathrm{T}_{0}-100 \%$ natural light, $\mathrm{T}_{1}-$ mild shade (70\% natural light), $\mathrm{T}_{2}-$ moderate shade (50\% natural light), $\mathrm{BT}_{0}-100 \%$ natural light $+0.1 \mathrm{mg}(\mathrm{BR}) \mathrm{L}^{-1}, \mathrm{BT}_{1}-$ mild shade $+\mathrm{BR}\left[70 \%\right.$ natural light $\left.+0.1 \mathrm{mg}(\mathrm{BR}) \mathrm{L}^{-1}\right], \mathrm{BT}_{2}-$ moderate shade $+\mathrm{BR}[50 \%$ natural light $\left.+0.1 \mathrm{mg}(\mathrm{BR}) \mathrm{L}^{-1}\right]$.

at each level of shade. Day mean values as well as different day time values did not suggest any significant effect of shade and BR spray on $E$. However, under natural light and moderate shade conditions, higher $E$ was found at 10:00 h, while under mild shade, maximum increase in $E$ occurred at 8:00 h. Overall, an increase in $P_{\mathrm{N}}$ and $g_{\mathrm{s}}$, and decrease in $E$ were noticed in their day mean values under shade, but this effect was not statistically significant (Table 2). Shade enhanced the most of the gas-exchange parameters in the order: mild shade $>$ moderate shade $>$ natural light, while it resulted in reduced $E$ and $C_{\mathrm{i}}$ as compared with control. The shade significantly increased $P_{\mathrm{N}}$ compared with natural light conditions and BR boosted up the shade effect insignificantly. The maximum $P_{\mathrm{N}}$ was observed at mild shade followed by moderate shade and natural light which were statistically same with each other. The $g_{\mathrm{s}}$ was not much affected by shade and BR spray, but stomatal limitation $\left(\mathrm{L}_{\mathrm{s}}\right)$ was maximum under both shade conditions. The $E$ significantly decreased under shade compared with control; it was minimum at moderate shade and 


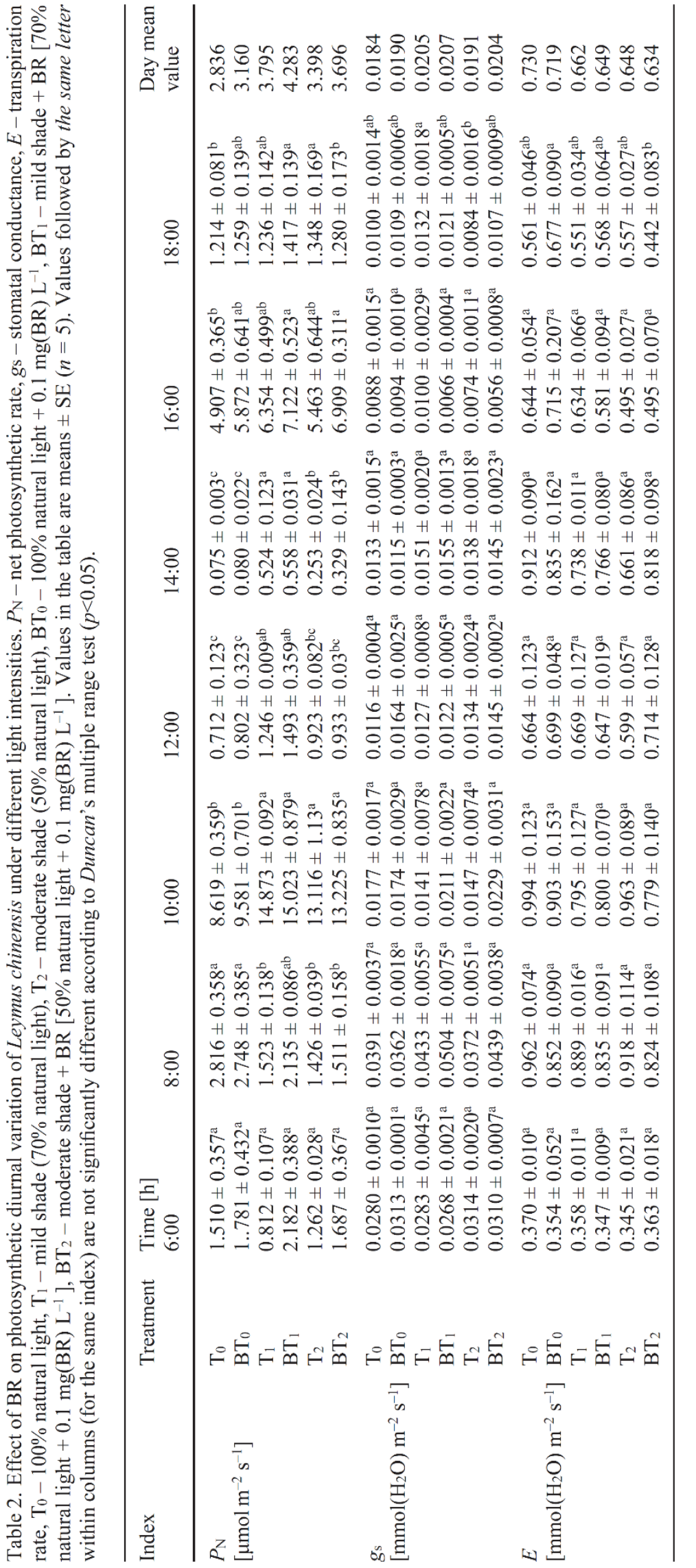

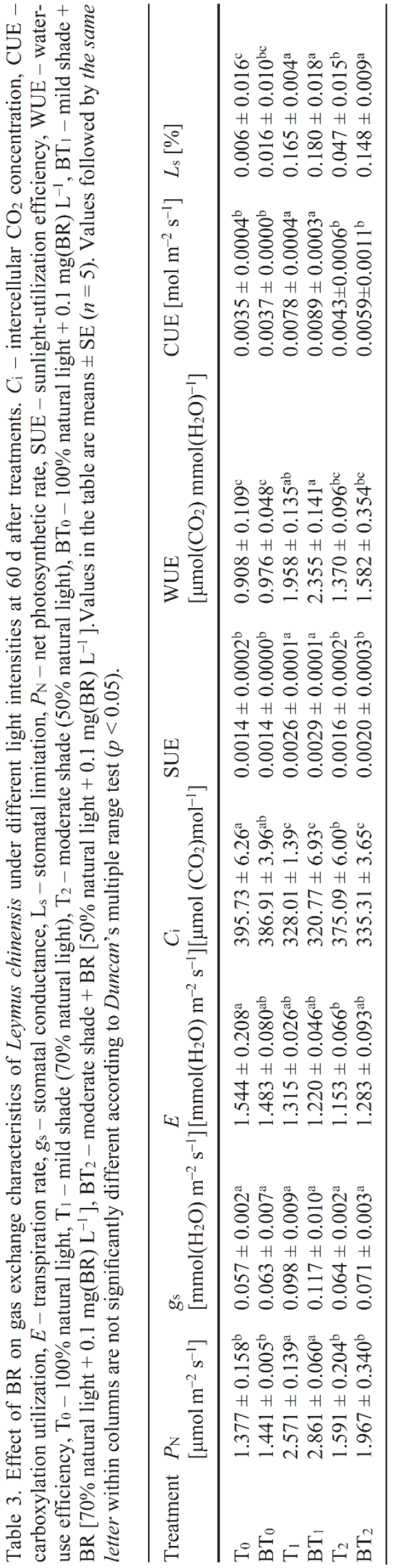




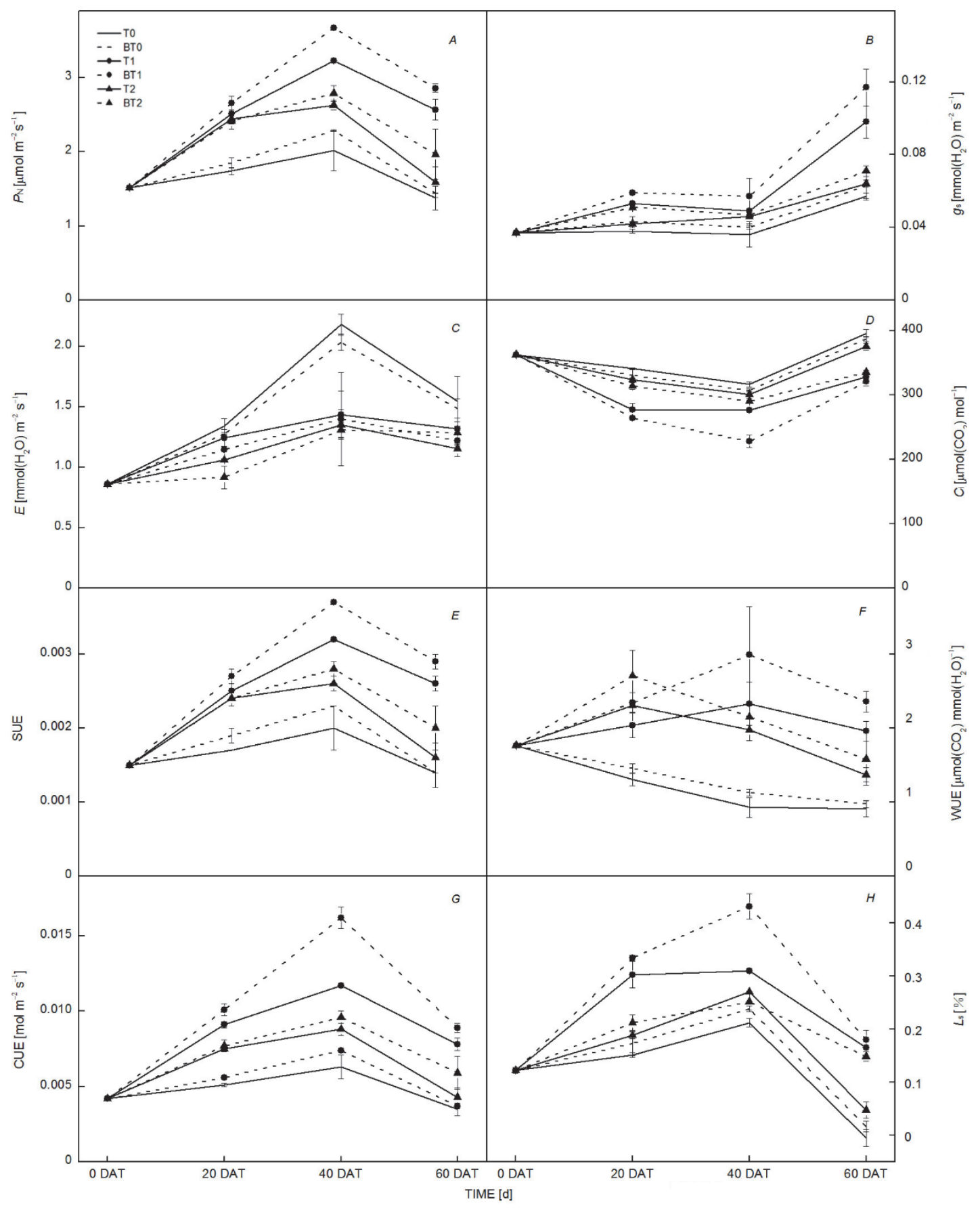

Fig. 3. Dynamic changes after BR treatment on gas-exchange characteristics of Leymus chinensis under different light intensities. Mean value $\pm \mathrm{SE}(n=5)$. DAT - days after treatments. $C_{\mathrm{i}}-$ intercellular $\mathrm{CO}_{2}$ concentration, $\mathrm{CUE}$ - carboxylation utilization, $E-$ transpiration rate, $g_{\mathrm{s}}$ - stomatal conductance, $\mathrm{L}_{\mathrm{s}}$ - stomatal limitation, $P_{\mathrm{N}}$ - net photosynthetic rate, SUE - sunlight-utilization efficiency, WUE water-use efficiency, $\mathrm{T}_{0}-100 \%$ natural light, $\mathrm{T}_{1}-$ mild shade (70\% natural light), $\mathrm{T}_{2}-$ moderate shade $\left(50 \%\right.$ natural light), $\mathrm{BT}_{0}-100 \%$ natural light $+0.1 \mathrm{mg}(\mathrm{BR}) \mathrm{L}^{-1}, \mathrm{BT}_{1}-$ mild shade $+\mathrm{BR}\left[70 \%\right.$ natural light $\left.+0.1 \mathrm{mg}(\mathrm{BR}) \mathrm{L}^{-1}\right], \mathrm{BT}_{2}-$ moderate shade $+\mathrm{BR}[50 \%$ natural light $\left.+0.1 \mathrm{mg}(\mathrm{BR}) \mathrm{L}^{-1}\right]$.

statistically different from control, i.e., normal natural light conditions. Shade significantly decreased $C_{\mathrm{i}}$ compared with natural light conditions. The minimum $C_{\mathrm{i}}$ values were observed at mild shade followed by moderate shade. Shade substantially increased sunlight-utilization efficiency (SUE), water-use efficiency (WUE), and carboxylation efficiency (CUE) compared with normal light conditions. However, BR spray did not boost shade effect for SUE, WUE, and CUE significantly. Maximum SUE, WUE, and CUE were observed at mild shade 
Table 4. Effect of BR on chlorophyll fluorescence traits of Leymus chinensis under different light intensities after 18 days of treatments. $\mathrm{DAT}$ - days after treatments, $\mathrm{F}_{0}$ - minimal fluorescence yield of the dark-adapted state, $\mathrm{F}_{\mathrm{m}}-$ maximal fluorescence yield of the darkadapted state, $\mathrm{F}_{\mathrm{v}} / \mathrm{F}_{\mathrm{m}}$ - optimal/maximal quantum yield of PSII photochemistry, $\mathrm{F}_{\mathrm{v}} / \mathrm{F}_{0}-$ optimal/minimal quantum yield of PSII or photochemical efficiency of PSII, ФPSII - photosynthetic quantum yield of PSII. T $0-100 \%$ natural light, $\mathrm{T}_{1}-$ mild shade $(70 \%$ natural light), $\mathrm{T}_{2}$ - moderate shade (50\% natural light), $\mathrm{BT}_{0}-100 \%$ natural light $+0.1 \mathrm{mg}(\mathrm{BR}) \mathrm{L}^{-1}, \mathrm{BT}_{1}-$ mild shade $+\mathrm{BR}[70 \%$ natural light $\left.+0.1 \mathrm{mg}(\mathrm{BR}) \mathrm{L}^{-1}\right], \mathrm{BT}_{2}-$ moderate shade $+\mathrm{BR}\left[50 \%\right.$ natural light $\left.+0.1 \mathrm{mg}(\mathrm{BR}) \mathrm{L}^{-1}\right]$. Values in the table are means $\pm \mathrm{SE}(n=5)$. Values followed by the same letter within columns are not significantly different according to Duncan's multiple range test $(p<0.05)$.

\begin{tabular}{llllll}
\hline Treatment & $\mathrm{F}_{0}$ & $\mathrm{~F}_{\mathrm{m}}$ & $\mathrm{F}_{\mathrm{v}} / \mathrm{F}_{\mathrm{m}}$ & $\mathrm{F}_{\mathrm{v}} / \mathrm{F}_{0}$ & $\Phi_{\text {PSII }}$ \\
\hline $\mathrm{T}_{0}$ & $29.932 \pm 1.389^{\mathrm{b}}$ & $135.175 \pm 6.82^{\mathrm{c}}$ & $0.778 \pm 0.004^{\mathrm{b}}$ & $3.527 \pm 0.252^{\mathrm{c}}$ & $0.214 \pm 0.023^{\mathrm{b}}$ \\
$\mathrm{BT}_{0}$ & $30.216 \pm 0.791^{\mathrm{b}}$ & $143.642 \pm 2.214^{\mathrm{bc}}$ & $0.790 \pm 0.002^{\mathrm{ab}}$ & $3.757 \pm 0.055^{\mathrm{bc}}$ & $0.239 \pm 0.025^{\mathrm{b}}$ \\
$\mathrm{T}_{1}$ & $41.098 \pm 1.463^{\mathrm{a}}$ & $217.285 \pm 8.585^{\mathrm{a}}$ & $0.811 \pm 0.001^{\mathrm{a}}$ & $4.286 \pm 0.025^{\mathrm{a}}$ & $0.367 \pm 0.024^{\mathrm{a}}$ \\
$\mathrm{BT}_{1}$ & $41.106 \pm 1.523^{\mathrm{a}}$ & $218.371 \pm 11.172^{\mathrm{a}}$ & $0.811 \pm 0.003^{\mathrm{a}}$ & $4.307 \pm 0.09^{\mathrm{a}}$ & $0.378 \pm 0.028^{\mathrm{a}}$ \\
$\mathrm{T}_{2}$ & $31.464 \pm 2.425^{\mathrm{b}}$ & $150.642 \pm 8.787^{\mathrm{bc}}$ & $0.792 \pm 0.006^{\mathrm{ab}}$ & $3.804 \pm 0.139^{\mathrm{bc}}$ & $0.282 \pm 0.023^{\mathrm{ab}}$ \\
$\mathrm{BT}_{2}$ & $33.418 \pm 0.968^{\mathrm{b}}$ & $168.681 \pm 3.561^{\mathrm{b}}$ & $0.802 \pm 0.002^{\mathrm{ab}}$ & $4.05 \pm 0.054^{\mathrm{ab}}$ & $0.292 \pm 0.031^{\mathrm{ab}}$ \\
\hline
\end{tabular}

followed by moderate shade (Table 3 ). The $P_{\mathrm{N}}, E$, SUE, CUE, and $\mathrm{L}_{\mathrm{s}}$ were elevated from 20 to 40 DAT followed by a decrease, while $g_{\mathrm{s}}$ and $C_{\mathrm{i}}$ declined from 20 DAT onwards until 40 DAT and then again increased until 60 DAT. However, a differential response was noticed in WUE, where under natural light and moderate shade condition, the maximum value was obtained at 20 DAT, while at mild shade, the maximum value was observed at 40 DAT. The $E$ followed the order: natural light $>$ mild shade $>$ moderate shade, while $C_{\mathrm{i}}$ at 20 and 40 DAT was in the order: natural light $>$ moderate shade $>$ mild shade, and at $60 \mathrm{DAT}$, the order was natural light $>$ mild shade $>$ moderate shade (Fig. 3).Chl fluorescence attributes of L. chinensis were significantly affected by shade, while BR application did not change Chl fluorescence attributes significantly at each level of shade. Shade increased the $F_{0}$ and $\mathrm{F}_{\mathrm{m}}$ over normal natural light conditions. Maximum values for $F_{0}$ and $F_{m}$ were observed under mild shade

\section{Discussion}

The increased growth of L. chinensis under shade was attributable to the enhanced biosynthesis of photosynthetic pigments and photosynthetic activity. Similar to our results, it has been reported that the growth of European yew improved with increased shade (Perrin and Mitchell 2013). Light is one of the primary factors affecting the plant growth and productivity through modulation of plant physiological processes and the light intensity has profound position in this context (Wang et al. 2016). The increase in L. chinensis growth by BR spraying under normal and shade conditions may be attributed to the positive modifications in the cell division and elongation (Fujii and Saka 2001, Vriet et al. 2012). Nassar (2004) reported an increase in height and biomass of banana plants by application of homobrassinolide under heat stress. Application of BR to plants can improve plant growth and development, but in the present study, BR did followed by moderate shade which was statistically same with normal natural light conditions. Shade also increased the optimal/minimal quantum yield of PSII or photochemical efficiency of PSII $\left(\mathrm{F}_{\mathrm{v}} / \mathrm{F}_{0}\right)$ and optimal/maximal quantum yield of PSII $\left(\mathrm{F}_{\mathrm{v}} / \mathrm{F}_{\mathrm{m}}\right)$ and photosynthetic quantum yield of PSII ( $\left.\Phi_{\text {PSII }}\right)$ significantly over control. Maximum values for $\mathrm{F}_{\mathrm{v}} / \mathrm{F}_{0}, \mathrm{~F}_{\mathrm{v}} / \mathrm{F}_{\mathrm{m}}$, and $\Phi_{\mathrm{PSII}}$ were observed at mild shade followed by moderate shade which was statistically as under natural light conditions. Overall, shade exaggerated all the $\mathrm{Chl}$ fluorescence attiributes of $L$. chinensis as compared to natural light and the order of increase was: mild shade $>$ moderate shade $>$ natural light (Table 4). $F_{0}$ and $F_{m}$ decreased first from 6-12 DAT and again increased until 18 DAT. The $F_{v} / F_{0}$ and $F_{v} / F_{m}$ continued decreasing from 6 until 18 DAT. $\Phi_{\text {PSII }}$ increased from 6 to 12 DAT and then decreased until 18 DAT. Improvement in Chl fluorescence attributes under shade was evident at each stage of growth (Fig. 4).

not influence photosynthetic pigments and photosynthetic activity significantly.

Photosynthetic pigments, such as $\mathrm{Chl} a$, Chl $b$, TChl, and $\mathrm{Car}$, increased linearly with the increase in shade, i.e., from $100 \%$ of natural light to $50 \%$ natural light. The increase in biosynthesis of photosynthetic pigments under shade indicated the acclimation of $L$. chinensis to low light conditions for capturing and utilizing maximum amount of light energy and enhancing photosynthetic efficiency (French and Moore 2003). Similar results were reported by Chaves et al. (2008) who observed an increase in Chl concentrations in coffee plants under low light conditions as compared to high light conditions. In our study, application of BR further increased the biosynthesis of photosynthetic pigments at each level of shade as observed in Lycopersicon esculentum due to BR spray (Hayat et al. 2011). Our results are in line with Janeczko et al. (2007) 


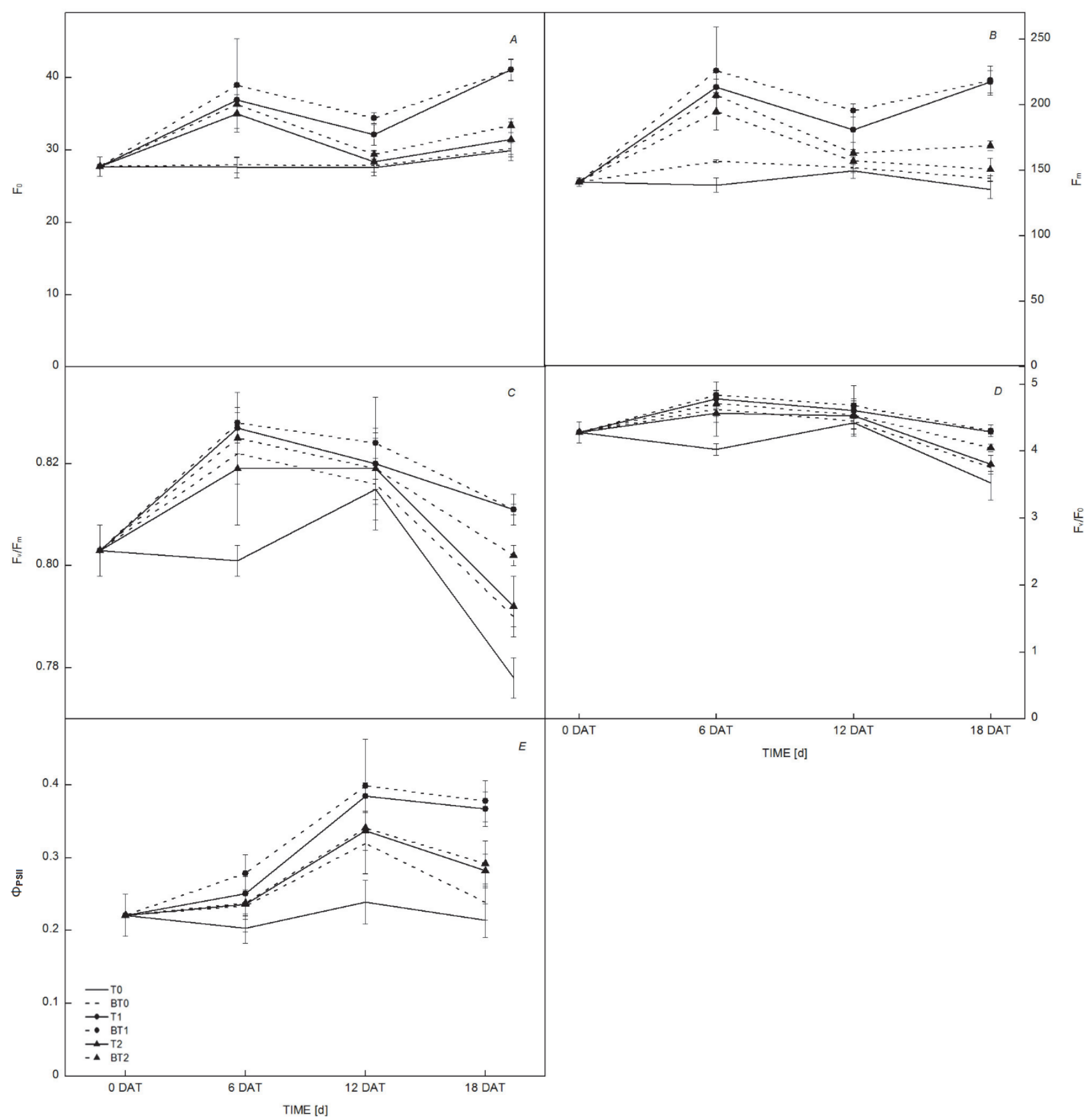

Fig. 4. Dynamic changes after BR treatment on chlorophyll fluorescence traits of Leymus chinensis under different light intensities. Mean value $\pm \mathrm{SE}(n=5)$. DAT - days after treatments, $\mathrm{F}_{0}$ - minimal fluorescence yield of the dark-adapted state, $\mathrm{F}_{\mathrm{m}}-$ maximal fluorescence yield of the dark-adapted state, $\mathrm{F}_{\mathrm{v}} / \mathrm{F}_{\mathrm{m}}$ - optimal/maximal quantum yield of PSII photochemistry, $\mathrm{F}_{\mathrm{v}} / \mathrm{F}_{0}-$ optimal $/$ minimal quantum yield of PSII or photochemical efficiency of PSII, $\mathrm{F}_{\mathrm{v}}$ - variable fluorescence, $\Phi_{\mathrm{PSII}}$ - photosynthetic quantum yield of PSII. T 0 - $100 \%$ natural light, $\mathrm{T}_{1}$ - mild shade ( $70 \%$ natural light), $\mathrm{T}_{2}$ - moderate shade $\left(50 \%\right.$ natural light), $\mathrm{BT}_{0}-100 \%$ natural light + $0.1 \mathrm{mg}(\mathrm{BR}) \mathrm{L}^{-1}, \mathrm{BT}_{1}-$ mild shade $+\mathrm{BR}\left[70 \%\right.$ natural light $\left.+0.1 \mathrm{mg}(\mathrm{BR}) \mathrm{L}^{-1}\right], \mathrm{BT}_{2}-$ moderate shade $+\mathrm{BR}[50 \%$ natural light + $\left.0.1 \mathrm{mg}(\mathrm{BR}) \mathrm{L}^{-1}\right]$

who reported higher concentrations of photosynthetic pigments in rape plants in response to BR application under low temperature stress.

The highest values of $P_{\mathrm{N}}$ at 10:00 h indicated that at this time, the light intensity was optimum for L. chinensis to have maximum photosynthetic efficiency, and mild shade (70\% natural light) further favored this increase. However, it was also observed that at peak sunshine hours, i.e., 12:00 and 14:00 h, $P_{\mathrm{N}}$ drastically dropped down. The reason behind this might be reduced efficiency of 
photosynthetic apparatus due to absorbance of excessive light energy, which causes inactivation of photosynthetic machinery through photoinhibition (Bertamini et al. 2006, Dai et al. 2009). Shade significantly increased the $P_{\mathrm{N}}$ during peak sunshine hours by reducing the photoinhibition phenomenon. Reduction in $P_{\mathrm{N}}$ at 8:00 (morning) was observed because at this time, PAR level is generally very low and shade treatment further blocked the sun light. The insignificant change in $g_{\mathrm{s}}$ and $E$ under shade and BR treatment might be due to the fact that these are normally temperature- and water-dependent.

Improvement in gas-exchange parameters under shade might be through exacerbation of antioxidants activity, and stomatal regulation under shade that resulted in better utilization of light energy and increased $\mathrm{CO}_{2}$ assimilation rate leading to enhanced photosynthetic efficiency (Chaves et al. 2008). Tang et al. (2015) reported an increase in photosynthetic rate of Torreya grandis seedlings under shade due to enhanced biosynthesis of photosynthetic pigments, better protection of photosynthetic machinery, and also due to ultrastructural changes in chloroplasts, such as increased number of grana, grana lamellae, and osmiophilic globule number and size.

Our results showed that the shade increased the $\mathrm{Chl}$ fluorescence attributes, i.e., $\mathrm{F}_{0}, \mathrm{~F}_{\mathrm{v}}, \mathrm{F}_{\mathrm{v}} / \mathrm{F}_{\mathrm{m}}, \mathrm{F}_{\mathrm{v}} / \mathrm{F}_{0}$, and $\Phi_{\text {PSII }}$ with maximum increase occurring under $70 \%$ natural light. In plants exposed to continuous high light, Chl fluores-

\section{References}

Allen D.J., Ort D.R.: Impacts of chilling temperatures on photosynthesis in warm-climate plants. - Trends Plant Sci. 6: 36-42, 2001

Augner M., Tuomi J., Rousi M.: Effects of defoliation on competitive interactions in European white birch. - Ecology 78: 2369-2377, 1997.

Augustine D.J.: Long-term, livestock-mediated redistribution of nitrogen and phosphorus in an East African savanna. - J. Appl. Ecol. 40: 137-149, 2003.

Baker N.R.: Chlorophyll fluorescence: a probe of photosynthesis in vivo. - Annu Rev Plant Biol. 59: 89-113, 2008.

Bertamini M., Muthuchelian K., Rubinigg M. et al.: Low-night temperature increased the photoinhibition of photosynthesis in grapevine (Vitis vinifera L. cv. Riesling) leaves. - Environ. Exp. Bot. 57: 25-31, 2006.

Björkman O., Demmig B.: Photon yield of $\mathrm{O}_{2}$ evolution and chlorophyll fluorescence characteristics at $77 \mathrm{~K}$ among vascular plants of diverse origins. - Planta 170: 489-504, 1987.

Cao Y.Y., Duan H., Yang L.N. et al.: Effect of high temperature during heading and early filling on grain yield and physiological characteristics in indica rice. - Acta Agron. Sin. 35: 512-521, 2009.

Chaves A.R.M., Ten-Caten A., Pinheiro H.A. et al.: Seasonal changes in photoprotective mechanisms of leaves from shaded and unshaded field-grown coffee (Coffea arabica L.) trees. Trees 22: 351-361, 2008.

Dai Y., Shen Z., Liu Y. et al.: Effects of shade treatments on the photosynthetic capacity, chlorophyll fluorescence, and chlorophyll content of Tetrastigma hemsleyanum Diels et Gilg. - Environ. Exp. Bot. 65: 177-182, 2009. cence declines due to combination of photochemical quenching $\left(\mathrm{q}_{\mathrm{P}}\right)$ and nonphotochemical quenching (NPQ) in order to avoid photodamage (Müller et al. 2001; Ensminger et al. 2006). Shade protects the plants from continuous high light. Plants subjected to high irradiances show usually lower values of $F_{v} / F_{m}$ than those, which are subjected to low irradiances (Björkman and Demmig 1987, Baker 2008). Demmig-Adams and Adams III (1992) reported that $\mathrm{F}_{\mathrm{v}} / \mathrm{F}_{\mathrm{m}}$ values were lower in Pacific yew foliage exposed to sun as compared to foliage grown in shade. Higher values of quantum yield of PSII under mild shade $(70 \%$ natural light) revealed that shade substantially nullified the effects of 100\% natural light. Between 6-20 DAT, concentrations of photosynthetic pigments, such as Chl $a$, Chl $b$, and Car, were the lowest under $100 \%$ natural light conditions but their concentration substantially increased under shade. Chl fluorescence attributes also increased, thus our results confirmed that shade significantly mitigated the effects of photoinhibition on plants.

Conclusion: Our results revealed that shade substantially enhanced the plant growth and biosynthesis of photosynthetic pigments by increasing the photosynthetic efficiency and chlorophyll fluorescence attributes of L. chinensis. Based on the present data, we cannot conclude that brassinolide correlated positively with shade regarding increase in growth and photosynthetic efficiency.

Demmig-Adams B., Adams W.W. III: Photoprotection and other responses of plants to high light stress. - Annu. Rev. Plant Phys. 43: 599-626, 1992.

Ensminger I., Busch F., Huner N.P.A.: Photostasis and cold acclimation: sensing low temperature through photosynthesis. - Physiol. Plantarum 126: 28-44, 2006.

French G.T., Moore K.A.: Interactive effects of light and salinity stress on the growth, reproduction, and photosynthetic capabilities of Vallisneria americana (Wild Celery). Estuaries 26: 1255-1268, 2003.

Fujii S., Saka H.: The promotive effect of Brassinolide on lamina joint cell elongation, germination and seedling growth under low-temperature stress in rice (Oryza sativa L.). - Plant Prod. Sci. 4: 210-214, 2001.

Fynn R.W.S., Morris C.D., Kirkman K.P.: Plant strategies and trait tradeoffs influence trends in competitive ability along gradients of soil fertility and disturbance. - J. Ecol. 93: 384394, 2005.

Gassmann A.J.: Effect of photosynthetic efficiency and water availability on tolerance of leaf removal in Amaranthus hybridus. - J. Ecol. 92: 882-892, 2004.

Haag J.J., Coupe M.D., Cahill Jr. J.F.: Antagonistic interactions between competition and insect herbivory on plant growth. - J. Ecol. 92: 156-167, 2004.

Hayat S., Yadav S., Wani A.S. et al.: Comparative effect of 28homobrassinolide and 24-epibrassinolide on the growth, carbonic anhydrase activity and photosynthetic efficiency of $\mathrm{Lyco}$ persicon esculentum. - Photosynthetica 49: 397-404, 2011.

Hodgkinson K.C., Müller W.J.: Death model for tussock perennial grasses: a rainfall threshold for survival and evidence 
for landscape control of death in drought. - Rangeland J. 27: $105-115,2005$.

Janeczko A., Gullner G., Skoczowski A. et al:: Effects of brassinosteroid infiltration prior to cold treatment on ion leakage and pigment contents in rape leaves. - Biol. Plantarum 51: 355-358, 2007.

Krause G.H., Weis E.: Chlorophyll fluorescence and photosynthesis: the basics. - Annu. Rev. Plant Phys. 42: 313-349, 1991.

Müller P., Li X.P., Niyogi K.K.: Non-photochemical quenching. A response to excess light energy. - Plant Physiol. 125: 15581566, 2001.

Nassar A.H.: Effect of homobrassinolide on in vitro growth of apical meristems and heat tolerance of banana shoots. - Int. J. Agri. Biol. 6: 771-776, 2004.

Niu J., Anjum S.A., Wang R. et al.: Exogenous application of brassinolide can alter morphological and physiological traits of Leymus chinensis (Trin.) Tzvelev under room and high temperatures. - Chilean J. Agri. Res. 76: 27-33, 2016.

Perrin P.M., Mitchell F.J.G.: Effects of shade on growth, biomass allocation and leaf morphology in European yew (Taxus baccata L.). - Eur. J. Forest Res. 132: 211-218, 2013.

Stitt M., Schulze D.: Does Rubisco control the rate of photosynthesis and plant growth? An exercise in molecular ecophysiology. - Plant Cell Environ. 17: 465-487, 1994.

Tang H., Hu Y., Yu W. et al.: Growth, photosynthetic and physiological responses of Torreya grandis seedlings to varied light environments. - Trees 29: 1011-1022, 2015.

van der Wal R., Egas M.,van der Veen A., Bakker J.: Effects of resource competition and herbivory on plant performance along a natural productivity gradient. - J. Ecol. 88: 317-330, 2000.

Vriet C., Russinova E., Reuzeau C.: Boosting crop yields with plant steroids. - Plant Cell 24: 842-857, 2012.

Wang R., Anjum S.A., Niu J. et al.: Exogenous application of brassinolide ameliorate chilling stress in Leymus chinensis (trin.) Tzvel. by modulating morphological, physiological and biochemical traits. - Bangl. J. Bot. 45: 143-150, 2016.

Wang R.Z., Li J.D.: Species diversity of main communities in South Songnen Plain. - Chin. J. Appl. Ecol. 7: 381-385, 1996.

Wellburn A.R.: The spectral determination of chlorophyll $a$ and chlorophhyll $b$, as well as total carotenoids, using various solvents with spectrophotometers of different resolution. - J. Plant Physio. 144: 307-313, 1994.

Wilson S.D., Tilman D.: Quadratic variation in old-field species richness along gradients of disturbance and nitrogen addition. - Ecology 83: 492-504, 2002.

Zhu X.D., He H.L., Liu M. et al.: Spatio-temporal variation of photosynthetically active radiation in China in recent 50 years. - J. Geograph. Sci. 20: 803-817, 2010. 